\title{
ЗАНЯТОСТЬ РОССИЙСКИХ ЖЕНЩИН ПОСЛЕ РОЖДЕНИЯ ДЕТЕЙ: СТИМУЛЫ И БАРЬЕРЫ
}

Основная задача статьи- проанализировать занятость женщин, имевших работу до отпуска по беременности и родам. Перерыв в трудовой деятельности обуславливает для данной категории рост незанятости, вызванный сочетанием стимулов и барьеров для выхода на работу. Соответствующие представления выявлены посредством качественного анализа данных групповых интервью и сравнения мнений незанятых и занятых женщин с детьми до трех лет, а среди занятых- высоко-, средне- и низкоквалифицированных работников с учетом социально-экономической неоднородности населения в поселенческом разрезе. Исследование выявило, что в период беременности и декретного отпуска стимулом/барьером возобновления занятости могут стать взаимоотношения с работодателем ввиду повышения риска потери работы и снижения заработной платы. Работодатели дают понять, что им не интересны подчиненные, которые будут сидеть на больничном с ребенком, иногда отдельно оговариваются условия их работы. Основным барьером занятости оказалась невозможность отдать ребенка в детское дошкольное учреждение. В селах и малых городах ясли и детские сады далеко от дома и в них невозможно устроиться. Крупные города формируют запрос на «хорошие сады» с подготовленными воспитателями и небольшими группами. Практически повсеместна проблема отсутствия ясельных групп. Барьерами для возобновления трудовой деятельности выступают невозможность брать больничный по уходу за ребенком, недостижимость гибкой занятости и дистанционной работы, установки семей на незанятость женщин и воспитание ребенка матерью,

Алина Игоревна Пишняк- к.с.н., заведующая Центром анализа доходов и уровня жизни, Национальный исследовательский университет «Высшая школа экономики», Москва, Россия. Электронная почта: apishniak@hse.ru

Евгения Владимировна Надеждина-к. культурологии, доцент кафедры экономической социологии, Национальный исследовательский университет «Высшая школа экономики», Москва, Россия. Электронная почта: nadezhda@hse.ru 
отсутствие рабочих мест и потеря квалификации за период отпуска. Главным стимулом для возобновления занятости является необходимость обеспечения затрат на витальные потребности семьи или (в крупных городах) на погашение кредитов и ипотеки. Выплаты по уходу за ребенком до полутора лет все опрошенные считают ощутимой поддержкой: даже высококвалифицированные специалисты хотели бы получать их после выхода на работу. Также стимулами возврата являются нехватка общения, установка на работу и боязнь «засидеться дома», потребность в самореализации и статусе, желание сохранить за собой место занятости, новое предложение о работе.

Ключевые слова: занятость женщин, рынок труда, возврат к занятости, отпуск по уходу, отпуск по беременности и родам

DOI: 10.17323/727-0634-2020-18-2-221-238

Одно из последствий изменений пенсионного законодательства заключается в том, что женщины будут вынужденно оставаться работающими дольше, чем в предшествующих поколениях. У этого решения есть негативные социальные последствия для работающих молодых женщин с несовершеннолетними детьми. Так, в России женщины по выходе на пенсию часто берут на себя заботу о внуках, давая возможность дочерям и невесткам вернуться к профессиональной деятельности. Это положительно сказывается на материальном положении семьи, кроме того, в этом случае молодые женщины имеют возможность не снижать свою квалификацию, что важно не только для работника, но и для экономики в целом. Эта практика теперь находится под угрозой.

Поэтому мы предлагаем обратиться к результатам исследования, проведенного Центром анализа доходов и уровня жизни ВШЭ. Его цельвыявление барьеров для возвращения женщин на рынок труда после рождения ребенка, и поиск стимулов возобновления трудовой деятельности. Занятость женщин с детьми исследуется во многих странах. Показатель доли работающих матерей варьируется и зависит, в том числе, от государственной политики (Aliaga 2005; Van Der Lippe 2001; Gornick et al. 1998). Ключевое значение имеют связанные с материнством и детством выплаты, опции институциального ухода за детьми, налоговые и субсидиарные решения и программы стимулирования гибкой занятости и дополнительного обучения (OECD 2011).

Исследования положения работающих матерей часто обсуждают распределение времени и анализируют бюджетные ограничения семьи (Becker 1991; Hotz, Miller 1988; Killingsworth, Heckman 1986). Однако более близкими к реальности представляются работы, учитывающие вклад социального окружения: помощь родственников, позволяющих выйти на работу (Jaumotte 2003), а также ценности и установки (Fortin 2006; Uunk et al. 2005),- не только доминирующий в обществе взгляд на совмещение 
материнства и занятости, но и внимание к дифференциации установок в разных группах женщин (Hakim 1996). Наличие «штрафа за материнство» с позиции рынка труда отмечается в исследованиях, реализуемых в разных институциальных и культурных условиях. Авторы пытаются объяснить неравенство позиций и заработных плат (Rubery et al. 1998) и подчеркивают, что проблема может быть более или менее острой для разных групп матерей- например, с разным уровнем образования (Correll et al. 2007).

В России вопрос занятости матерей исследуется в основном в оптике поиска групп, для которых рождение ребенка несет наибольший риск потери работы. Само наличие этого риска фактически не ставится под сомнение (Пишняк 2015; Пайе, Синявская 2010; Синявская и др. 2007; Рощин 2003). В исследовании, посвященном предложению рынка труда в России (Рощин 2003), показано, что экономическая активность женщин в возрасте 25-29 и 30-34 лет снижается (именно в это время в семье появляются первый и второй ребенок). Наличие детей отрицательно влияет на занятость, хотя трудовая активность замужних женщин выше, чем незамужних. Наличие постоянного дохода мужа должно, по идее, снижать экономическую активность жены, ведь имеющийся доход является общим в домохозяйстве, а заработок жены рассматривается как вспомогательный, поддерживающий бюджет семьи, и как «подушка безопасности» на случай потери работы супругом. Налицо, между тем, «парная занятость», объясняемая Сергеем Рощиным трансляцией социального капитала: супруг(а) выбирает аналогичный образ жизни, получая дополнительные возможности для трудоустройства благодаря работающему(ей) супругу(е).

Конфликт между занятостью и материнством становится предметом изучения и в области социальной политики. Исследователи отмечают, что работающие женщины с высшим образованием- наиболее перспективная в плане роста рождаемости группа, но такая перспектива требует выполнения трудового законодательства и развития системы дошкольных учреждений (Синявская и др. 2007). Чтобы обеспечить возвращение к труду высокообразованных женщин, государству следует также развивать дополнительное образование. На индивидуальном уровне на выбор возврата к работе влияет состав домохозяйства: наличие родственников, готовых взять на себя часть заботы о ребенке.

Негативным следствием рождения ребенка оказывается риск оказаться после возвращения на рынок труда в менее выгодных условиях по сравнению с работницами, не имеющими детей (Ниворожкина и др. 2008). Известно, что чем дольше перерыв в занятости, тем выше вероятность проблем с трудоустройством (Гимпельсон и др. 2003; Гимпельсон, Ощепков 2010). Нельзя утверждать, что это обусловлено лишь потерей квалификации в период декрета, однако данный фактор, очевидно, вносит свой вклад. Особенно это важно в контексте того, что семьи с детьми в России неизменно оказываются среди групп с повышенными рисками бедности (Popova, Pishnyak 2017). 
Возникает ряд вопросов: почему одни возвращаются к работе, а другие остаются вне рынка труда? Что удерживает женщин от выхода на работу, и что могло бы помочь им в этом? За ответами в обратимся к результатам качественного исследования, чтобы выявить представления женщин с детьми о стимулах и барьерах занятости.

Поскольку большинство женщин, работавших до родов, возвращается к занятости, когда ребенку исполняется три года (Пайе, Синявская 2010), интерес представляет предшествующий этому период, когда препятствия для возвращения к занятости велики. При этом тема первичного выхода на работу после декрета соответствует в большей степени вопросу трудоустройства без опыта занятости, мы же сделаем акцент на тех, кто до декретного отпуска имел подобный опыт. Для выявления и стимулов, и барьеров потребуется компаративный анализ как занятых, так и незанятых. Однако категория занятых неоднородна: уровень квалификации дифференцирован. Есть основания предполагать, что женщины- в зависимости от квалификационных требований своей работы,- имеют разные стимулы для возвращения к трудовой деятельности (Пишняк 2015). Хотя качественный анализ не претендует на репрезентативность, мы сопоставим мнение высоко- и средне/низкоквалифицированных работников.

С учетом вышесказанного, эмпирическую основу исследования представляют материалы десяти фокус-групп с участием занятых и незанятых женщин (различного уровня квалификации), с детьми в возрасте до трех лет и проживающих в различных типах поселения. В исследовании приняли участие 80 женщин. Рекрутирование респондентов фокус-групп проходили в четырех типах населенных пунктов: столица (Москва); крупный город, областной центр (Архангельск); малый город (Каргополь); село (Шалакуша). Все до рождения ребенка работали. Отбор респондентов осуществлялся в соответствии с параметрами спецификации объекта исследования. В групповых дискуссиях приняли участие женщины различных возрастов. Наибольшее представительство было обеспечено группам 25-29 и 30-35 лет. В дискуссиях участвовали респонденты с разным числом детей: у большинства только один ребенок (59\%), у трети двое детей (31\%), трое или больше детей у $10 \%$ женщин. При этом у $15 \%$ дети до года, у примерно $36 \%$ от года до двух, а у $49 \%$ младшему исполнилось два.

\section{Взаимоотношения с работодателем перед отпуском по беременности и родам}

Результаты анализа показывают, что одни женщины договариваются с руководителями о последующем возврате на работу, другие видят, что на то же место работы не вернутся, третьи готовятся отвоевывать должность, с которой уходят в декрет. На фокус-группах отмечали опасения перемены отношения работодателя и коллег после известия о беременности 
на основе негативного опыта знакомых, или предупреждения о нежелательности ухода в декрет при приеме на работу1: «Увольняют в 6 месяцев, я знаю таких, когда беременных увольняют, чтобы не платить потом» (Занятые, Москва). Об этом опыте говорили и занятые, и незанятые, но первые приводили гораздо больше примеров и говорили гораздо эмоциональнее, чем вторые: «Уволить даже могут заочно. Знаю там, когда пишешь заявление на увольнение без числа <..> И если ты декретница, тебя лишают премии - 100\% лишают» (Занятые, Архангельск). Особое внимание этому вопросу уделяли москвички, в селе данная тема не вызвала отклика.

Респонденты отмечают, что «беременность сотруднии никаким работодателем не приветствуется». Нередко об этом говорят еще при приеме на работу: «Когда берут на работу, заранее предупреждаютникаких декретов, не вздумайте беременеть» (Занятые, Архангельск); «Я знаю компании, где руководители если не письменные расписки [берут], то устно проговаривают, что: "Как только беременеете, пишите заявление об уходе"» (Незанятые, Москва). Учитывая это, некоторые сразу ищут организацию, где риск потери работы и дохода во время беременности будет минимален: «Я на самом деле долго искала компанию, из которой можно уйти в декрет: белая зарплата, хороший начальник и т.д.». (Занятые высококвалифицированные, Москва).

Таким образом, отношения с работодателем в период, предшествующий декретному отпуску, могут стимулировать или, напротив, демотивировать возвращение к работе после рождения ребенка. У женщин возникали опасения, что на работе негативно отнесутся к их беременности и будут провоцировать увольнение или урезать выплаты. Но в малом городе и селе меньше переживают из-за этого: нет такой конкуренции, и рабочие места не столь привлекательны по условиям и оплате.

Опыт респондентов не дает оснований утверждать, что нарушение прав работодателем повсеместно. Все же несколько суждений участниц фокус-групп обращались к этой проблеме:

Я в пять месяцев ушла с той работы, потому что меня 5-месячную посылали в командировку. Мы рассорились, и я попала в больницу на сохранение. Я подавала на них в прокуратуру, потому что мне не выплатили ни копейки декретных (Незанятые, Москва).

Столичные работодатели как правило не идут на прямое нарушение закона, самая популярная стратегия- создать невыносимые условия работы: «Конечно, официально вас никто не уволит, по закону <... У Уловия создадуm, и уволишься сам» (Занятые высококвалифицированные, Москва). Не в Москве имеют место более жесткие сценарии. Например, пользуясь

\footnotetext{
1 В тексте понятия «отпуск по уходу за ребенком» и «декретный отпуск» используются как тождественные.
} 
невнимательностью/некомпетентностью работницы, работодатель получает ее подпись, позволяющую уволить без нарушения буквы закона, или просто увольняет беременную:

[Мне] сказали подписать бумажку-там работаешь до такого-то срока, потом увольняешься, уходишь и получаешь компенсацию (какие-то деньги). Ну, я проработала в таком варианте. Потом за неделю сказала, что все, ухожу. И мне сказали: вы уже месяц как бы не работаете. Вы уволены (Незанятые, Каргополь).

Но есть и те, кто знал, что проблем с уходом в декрет и возвращением после него не будет: «То есть я знала, что меня никто не подсидит, не уволит. Что я получу все свои компенсации. Мне выдали и отпускные все, и всевсе» (Занятые, Архангельск). Однако так говорят вышедшие из отпуска до его окончания и по настоянию работодателя. Возможно, именно гарантия скорого возвращения служит залогом лояльного отношения к уходу в декрет.

Фактически все причины не иметь сотрудниц с маленькими детьми сводятся к стремлению руководителя убрать из штата тех, для кого риск выпадения из рабочего процесса намного выше, чем для других:

Если у тебя [дети маленькие], это подразумевает, что у тебя будут больничные листы. Потому что у нас мамы больше следят за детьми. Поэтому это нигде не приветствуется, ни в каких компаниях $<\ldots>$ : «Ой, у тебя ребенок еще детсадовский, он, наверное, болеет часто?» (Занятые высококвалифицированные, Москва).

Независимо от места проживания участники групп согласны только с одним: работодатель не хочет иметь дело с больничными: «Hy, вот больничные нежелательны. Вот я вышла на работу, у меня ребеночек маленький. Так они говорят: "Ага, вот вышла на работу, будешь на больничных часто сидеть"» (Занятые, Шалакуша). По мнению женщин, работодатель может сделать реальные шаги для увольнения или, по крайней мере, пригрозить работнице этим: «Я пришла на работу, меня сразу предупредили: "как только сядешь на больничный, всё, мы берём продавца нормального"» (Занятые, Каргополь). Незанятые, указывая причину нежелания работодателя видеть в штате женщину с ребенком, сразу говорили лишь о необходимости постоянно отпускать её на больничный.

\section{Возвращение на работу: желание, стимулы, барьеры}

Исследования показывают, что большинство выходит на работу в течение трех лет после рождения ребенка. Фокус-группы позволяют ответить, оптимален ли трехлетний отпуск по уходу или он короче/длиннее необходимого. Почему одни возвращаются еще до истечения отпуска, а другие остаются дома даже после его завершения? Речь идет не только об опти- 
мальном перерыве, но и о стимулах и барьерах для возобновления занятости. Например, считают ли женщины причиной раннего выхода на работу страх утраты квалификации, или напротив, потеря квалификации-это «якорь», удерживающий женщину дома?

Что говорят участницы фокус-групп о том, когда женщины хотели бы вернуться к труду, если бы тому не было никаких препятствий? Во всех группах незанятые респонденты отвечают, что как только ребенку исполнится три. При этом выход на работу до этого срока неприемлем. Тем не менее в словах горожанок (за исключением Москвы) прозвучало, что при наличии всех условий для выхода на работу можно и не дожидаться трех лет. А жительницы села, напротив, отметили, что в этом случае, возможно остались бы дома «до школы».

Занятые в основном солидарны с незанятыми по поводу выхода через три года. При этом все респонденты из областного центра обсуждали выход на работу по достижению ребенком года, но те, у кого это первый «декрет», хотят вернуться к работе раньше, а мамы нескольких детейпобыть в отпуске подольше:

Знаете, когда у меня [старшая дочь] была маленькая много лет назад, я вышла в год. Я очень жалею. Я не заметила, как она выросла. А сейчас я бы спокойно с удовольствием посидела бы до 3-х лет, если бы [могла], что называется (Занятые, Архангельск).

Эти женщины отмечают, что желание подольше быть с ребенком обусловлено не только материнством, но и отсутствием необходимости «работать на карьеру». Некоторые считают, что могут позволить себе перерыв благодаря достигнутому уровню в профессии, а часть с возрастом уже не так ценит карьерное развитие: «У меня отличные отношения с руководством. Mы, планируя ребенка, знали, что работой я никак не жертвую. Все было гладко, спокойно. Все в силу возраста. И время поменялось» (Занятые, Архангельск).

Нужно отметить существенное отличие высококвалифицированных от других столичных работниц. Менее квалифицированные респонденты утверждают, что имея возможность, были бы с ребенком до трех лет: «После трех уже женшине трудно выйти. Многие не хотят-проходит уже весь азарт зарабатьвания денег. Уже привыкаешь вроде» (Занятые, Москва). А высококвалифицированные предпочли бы не возвращаться на работу пять, семь или даже девять лет: «В основном, если женщине позволяют условия, какая она ни была б, даже более успешная, с хорошей карьерой, она лучше останется с ребенком» (Занятые высококвалифицированные, Москва). Но есть и другая причина- неудовлетворенность своей работой и желание в отпуске посвятить себя чему-то, не требующему присутствия в офисе и жесткого графика: «[Была бы возможность], я бы не работала, а хобби своим занималась» (Занятые высококвалифицированные, Москва). 
Подчеркнем, что незанятые женщины хотят выйти на работу как только ребенку исполнится три года. Таким образом, срок отпуска, возможно, будет для них идеален. Анализ данных показал, что снятие некоторых барьеров является стимулом для возобновления занятости, но нет причин считать, что все стимулы и барьеры связаны между собой именно так.

\section{Барьеры для выхода на работу}

Категоризация суждений участниц фокус-групп о препятствиях для выхода на работу представлена в таблице 1.

Таблица 1 .

Барьеры для выхода на работу

\begin{tabular}{|c|c|c|c|}
\hline Барьеры & 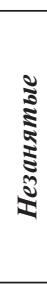 & 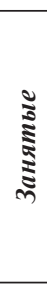 & 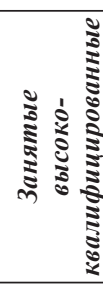 \\
\hline Невозможность отдать ребенка в ясли/детский сад & + & + & + \\
\hline Не с кем оставить ребенка & + & + & \\
\hline $\begin{array}{l}\text { Невозможность работать } \\
\text { по гибкому графику или дистанционно }\end{array}$ & + & & \\
\hline Болезни ребенка и невозможность брать больничный & + & + & \\
\hline Недостаточная материальная обеспеченность & & + & + \\
\hline Установка «мать должна быть с ребенком» & + & + & \\
\hline Установка на незанятость женщины & + & + & \\
\hline Отсутствие работы & & + & \\
\hline Потеря квалификации & + & & \\
\hline
\end{tabular}

Анализ ответов проводится сравнением различий в поселенческом разрезе. Так, для всех категорий основным барьером оказалась невозможность отдать ребенка в ясли/детский сад. Но в разных группах понимали это по-разному. В малом городе и селе барьером была удаленность детских учреждений: «Не устроить в сад. Даже в платный: был такой у нас-закрыли» (Незанятые женщины, Каргополь); «Нет садов поблизости» (Занятые, Шалакуша). В Москве и областном центре имели в виду дефицит мест в садах и отсутствие ясель: «Потому что в детский садик не дают места. Нет сада. Только в три года [можно будет ребенка отдать в сад]» (Незанятые, Архангельск). Кроме того, москвички упоминали качество услуг детсада и яслей: тревожит не невозможность отдать туда ребенка, а переполненность групп и некомфортная среда:

[Нужны] детские сады, с маленьким количеством человек в группе, с беспроблемным устройством, а не таким, какое сейчас существует. 
С нормальной близостью к дому, с инфраструктурой детского сада (Незанятые, Москва).

Еще одна проблема- «не с кем оставить ребенка»- выделяется отдельно, т. к. график работы сада и родителей может различаться, а также случается, что матери нужен больничный. То есть барьером для занятости становится отсутствие возможности работать по гибкому графику или дистанционно. Зачастую в таких ситуациях выручают бабушки: «[Mне] вообще не разрешают сидеть на больничном. А дети брошены на бабушек» (Незанятые, Каргополь). И занятые говорят, что выходом на работу обязаны только им.

Барьером возвращения могут быть и установки в семье. Убеждение, что мать должна много времени проводить с ребенком, или установка на незанятость женщины- труднопреодолимы. Но для отказа от занятости жены, у семьи должен быть хороший общий доход: «Можно сидеть [с ребенком], если есть финансовый тыл, заработок большой у мужа» (Занятые высококвалифицированные, Москва). При этом следует учитывать и минимальный стандарт потребления женщины без заработка в селе и малых городах:

Вот пойдет [мама малыша на работу] куда-то продавцом в магазин: там нужно отстоять, ребенка куда-то пристроить < .. > [Подумает и] скажет: «Да не пойду я, мне и так хватит» (Занятые, Шалакуша).

Незанятые москвички отметили, что причиной раннего выхода на работу может быть опасение потери квалификации. Видимо в Москве оборот технико-нормативной базы работы фирм происходит быстрее, и нет дефицита кадров. Причем речь шла лишь о страхе новых вызовов: «Боятся, что забыли что-то, что будут ошибаться постоянно, начальство будет носом тыкать <...> Они может и умные и за неделю вспомнят, но именно боятся» (Незанятые, Москва).

\section{Стимулы для выхода на работу}

Причины для выхода на работу в сроки ранее оптимальных, по мнению женщин, трех лет, имеют различное обоснование: работа-источник дохода, показатель статуса, место общения (табл. 2). Всех респондентов к возвращению в основном подталкивают финансовые мотивы:

Знаете, женщинам оплачивают декретный только до полутора лет. Дальше, извините, полтора года за свой счет в наше время. А ребенок растет, требует финансовых вложений (Занятые высококвалифицированные женщины, Москва).

В крупных городах их иногда трактовали как желание накопить на отдых или иметь собственные деньги. Важный финансовый мотив-кредиты: «Я вылила на работу [через полтора года], так как перестали платить деньги, и были кредиты» (Занятые, Архангельск). В селе и малых городах- 
это необходимость иметь хоть какие-то деньги: «Чтоб детей одевать, кормить, работать нужно. Вот и весь сказ» (Занятые, Шалакуша).

Таблица 2.

\section{Стимулы возврата к занятости}

\begin{tabular}{|c|c|c|c|}
\hline Стимуль & 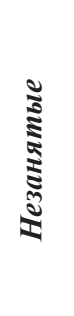 & 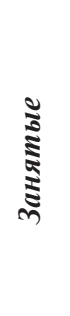 & 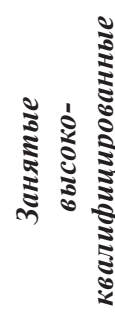 \\
\hline Финансовые & + & + & + \\
\hline Дефицит общения & + & + & + \\
\hline Установка на работу и страх «засидеться дома» & + & + & \\
\hline Потребность в самореализации & + & + & \\
\hline Статус & & & + \\
\hline Сохранить за собой место & & + & \\
\hline Новое предложение о работе & & + & \\
\hline Снятие барьеров как стимул & & & \\
\hline Возможность отдать ребенка в ясли/сад & + & + & + \\
\hline Гибкая занятость & + & + & + \\
\hline
\end{tabular}

Еще одним стимулом называли нехватку общения: «Без работы общения не хватает» (Занятые, Каргополь). - в крупных городах этим обеспокоены больше:

Да, я люблю сына, люблю заниматься с ним, но надо на работу, потому что хочется общения, хочется нового что-то. Тяжело сидеть-деградируешь. На работе ты как-то развиваешься с людьми, кто-то что-то тебе рассказал, ты что-то новое услышала. [Дело] даже не в самой работе, а [в том], что ты общаешься (Занятые, Москва).

Также упоминали желание «не засидеться дома». Речь шла не о самореализации (иногда она шла через запятую), но о страхе остаться незанятой: «Мне кажется, знаете, еще из-за чего, чтобы опять же когда работаешь, голову, мозг напрягаешь. Когда не работаешь [находишься] в расслабленном состоянии» (Занятые высококвалифицированные, Москва); «Не хочется такой [незанятой] тетехой быть» (Незанятые, Москва).

Высококвалифицированным москвичкам важна занятость как статус в глазах детей. Она выступает характеристикой индивида, и одним из стимулов возвращения является потребность в статусе:

Ребенку очень важно, кем станет его мама. Ему было бы очень приятно сказать: «Моя мама- начальник отдела кадров, а моя мама- главный 
бухгалтер организации. Она может то-то и то-то сделать». А не сказать: «Моя мама- домохозяйка» (Занятые высококвалифицированные, Москва).

Следующий стимул- желание сохранить за собой место работы,- не зависит от места жительства респондента. Высококвалифицированные понимают, что в случае длительного отсутствия их место может быть занято: «Не то чтобы меня принуждали, чтобы я вернулась. Я просто иенила свое место» (Занятые высококвалифицированные, Москва). Другие категории возобновляют занятость ввиду угрозы потери рабочего места: «Мне просто так еще подсказали: "Ты выходи, или сейчас берут новую девочку"» (Занятые, Москва); «Если бы до 3-х лет сидела дома, то хотели сократить мою долэность. Поэтому пришлось выйти» (Занятые, Шалакуша). Упоминалось, что с высоких должностей вовсе не уходят в отпуск, чтобы сохранить за собой место:

Моя начальница не уходила в декрет. Она просто нам всем объяснила: «16-го числа я рожаю, две недели меня не беспокойте». И уже после двух недель на телефоне давала какие-то указания <...> У нее руководящая должность, она понимала, что если уйдет, то уйдет навсегда (Занятые высококвалифицированные, Москва).

Иногда стимулом может стать новое предложение о работе, а для сельчан - сам факт её наличия: «Я вышла раньше, потому что мне предложили должность повыше. Сказали: "Если выйдешь сейчас, то будешь старшим продавиом, будешь сидеть дома-будешь обычным продавцом". Я решила выйти» (Занятые, Каргополь).

Следующие виды стимулов объединяет гипотеза, что побудить к выходу на работу может снятие барьеров. Речь прежде всего об услугах яслей/детских садов: дополнительные места, ясельные группы, качество работы: «Пойдут многие [на работу], если с полутора лет [детей в сад] будут брать» (Незанятые, Архангельск); «[Стимул для выхода на работу] - чтобы можно было ребенка устроить в сад» (Незанятые, Каргополь); «Чтобы с садиком не было проблем-самое главное» (Незанятые, Шалакуша). Уверенно говорилось о подобном эффекте гибкой занятости (работа полдня, свободный график, дистанционная работа): незанятые готовы к работе на таких условиях. Но договориться об этом удается редко, даже если производственные нужды не задеты: «На свою работу я, естественно, не пойду: с 9 до 5 часов- это тяжело. Но, допустим, 2-3 часа в день, я бы могла посвятить работе» (Незанятые, Архангельск); «[Вышла бы, если] рабочий день у меня был не целье сутки, чтобы с ребенком можно было находиться побольше» (Незанятые, Шалакуша).

\section{Потеря квалификации- мнимая проблема?}

На фокус-группах редко обсуждалась потеря квалификации за время отпуска. Поэтому важно понять, ощущается ли недостаток знаний и навыков 
после декрета. Хотя часть занятых утверждает, что не испытывали никаких сложностей, некоторые женщины с детьми до трех лет, возобновляя занятость, столкнулись со следующими проблемами. Во-первых, им было сложно входить в рабочий график:

[Вернулась на работу и] почувствовала себя такой глупой. Во-первых, нужно было войти в режим, потому что с 9 до 6 работа, а ты отвык. Весь день надо за собой следить, соответствовать в одежде, макияже. Какие-то люди к тебе обращаются с бумагами (Занятые, Москва).

Во-вторых, многим трудно восстановить прежние знания и навыки: «Если ты долго не работаешь, забываешь [специфику]. Я по своим тетрадкам, по учебникам вот это все вспоминала как будто заново. Конечно, вспомнила все, но тяжеловато было» (Занятые, Москва). Наконец, приходится осваивать нововведения: «[На работе] все обновляется, там все другое с каждый разом, каждый месяи. И ты как глупышка сидишь, и тебя учит [тот, кто пришел] на твое место, поработал там 6 месяцев» (Занятые, Москва). При этом высококвалифицированные утверждают, что адаптация заняла у них пару недель; у одних это был обычный рабочий процесс, у других вызвало некоторое напряжение: «Скажем так, глобально ничего не поменялось, так только по мелочам изменения были» (Занятые высококвалифицированные, Архангельск); «Первые две недели было тяжеловато, компьютерные программы вспоминала, потом анализаторы добавились, ну приказы немножко поменялисы» (Занятые высококвалифицированные, Архангельск). Более того, возобновление рабочей деятельности может быть чревато стрессом:

Я выходила с таким страхом, будто я забыла все. Я вышла на работу с пустой головой. У меня такое ощущение было первую неделю, что не помню вообще ничего. Хотя вот, вроде, все знакомое, бухгалтерия, но я от элементарных вещей прямо в шоке сидела (Занятые высококвалифицированные, Москва).

Некоторые респондентки по инициативе работодателя прошли курсы повышения квалификации перед выходом на работу. Потеря квалификации и адаптация при возвращении на работу не часто упоминались как особая проблема. Видимо, барьеры к возобновлению занятости (например, нежелание брать работниц с детьми назад) гораздо выше, чем профессиональные сложности.

Обратимся к суждениям респонденток о смене работы после рождения ребенка. Анализ показывает, что отпуск по уходу считается неподходящим временем для смены работы, об этом можно думать, когда ребенок подрастет: «Когда постарше-ребенку уже 4-5 лет-вот это подходящий [момент], когда все более или менее устаканилось. Ребенок [пошел] в садвот это уже нормально» (Занятые, Москва). При этом респондентки 
во время декретного отпуска и по уходу за ребенком делали ремонт, брали ипотеку и другие кредиты, меняли машины, поступали в вузы, что говорит о наличии свободного времени и для поиска новой занятости.

Тем не менее часть занятых участниц поменяла работу после рождения ребенка, а часть незанятых собирается искать что-то с более подходящими условиями. Уже сменившие работу объясняют это тем, что получили более выгодное предложение; пришлось уволиться, ввиду требования выйти на полный день; уволены с прежнего места работы; переведены во время отпуска по уходу на другую должность и отказались от нее. Лишь первая причина обусловлена личным решением работницы, остальные- вынужденная смена работы, при этом третья и четвертая связаны с незаконными действиями работодателя. Таким образом, смена работы в период отпуска по уходу представляется вынужденной: за выходом на новое место стоит невозможность оставаться на прежнем.

\section{Заключение}

Анализ специализированных фокус-групп с женщинами, воспитывающими детей в возрасте до трех лет, позволяет сделать ряд значимых заключений об их занятости, в том числе о барьерах и стимулах выхода на работу. Таковыми в период беременности и отпуска по уходу являются взаимоотношения с работодателем. В это время высок риск потери работы: увольнение после известия о беременности, сокращение во время декрета, снижение зарплаты. Хотя о повсеместных нарушениях прав работниц в этот период не сообщалось, работодатели дают понять, что мамы маленьких детей ввиду частых больничных нежелательны, и иногда оговаривают условия, на которых только и готовы привлекать их к работе.

Респондентки считают идеальным сроком отпуска по уходу три года, но при определенных условиях некоторые готовы приступить к работе раньше. Со вторым ребенком, как правило, остаются в отпуске дольше, поскольку уже чувствуют себя профессионалами, либо, напротив, теряют интерес к карьере. В любом случае, вернуться на работу раныше непросто- основным барьером занятости признана невозможность отдать ребенка в ясли или сад. В селах и небольших городах сады находятся далеко от дома и в них нет мест. А крупным городам нужны «хорошие сады» с современными педагогами и малым числом детей в группах. Почти нигде нет яслей.

Также барьерами занятости женщин выступают невозможность брать больничный, отсутствие гибкой занятости и дистанционной работы, установка на незанятость женщины, на воспитание ребенка матерью, отсутствие подходящих рабочих мест, потеря квалификации за период отпуска.

Главный стимул для возврата к труду- финансовый. В крупных городах это нужда в средствах на выплату кредитов/ипотеки, в небольших населенных пунктах - на повседневные нужды. В последних доход женщины 
часто становится основным, по окончании выплат по уходу за ребенком до полутора лет многие вовсе не могут прокормить семью. Это пособие весомо для всех: даже высококвалифицированные пытаются найти способы, чтобы получать его и после выхода на работу. Стимулами возврата к труду также являются дефицит общения, установка на работу и страх «засидеться дома», потребность в самореализации и статусе, желание сохранить за собой место, предложение о новой работе.

Перечисленные стимулы и барьеры можно классифицировать: социальные (барьер- установка на незанятость, стимул- общение с коллегами); экономические (барьер- нехватка денег на няню, стимул- возможность заработка); институциальные (барьер- дефицит детсадов; стимулсоздание яслей). Некоторые стимулы и барьеры можно отнести только к одной категории, другие- одновременно к нескольким. Невозможность на время оставить ребенка связана и с дефицитом мест в садах (институциальный барьер), и с дефицитом средств на частный сад (экономический барьер). Целью мер кратко- и среднесрочной социальной политики может быть снятие экономических и институциальных барьеров, создание экономических стимулов и новые решения. Преодоление же социальных барьеров требует дополнительного анализа.

\section{Выражение признательности}

Использованы результаты проекта «Анализ социально-экономического неравенства и перераспределительной политики, оценка уровня и качества жизни различных социальных групп и исследование факторов здорового и активного долголетия», выполненного в рамках Программы фундаментальных исследований НИУ ВШЭ в 2017 г.

\section{Список источников}

Гимпельсон В.Е., Капелюшников Р. И., Ратникова Т. А. (2003) Велики ли глаза у страха? Страх безработицы и гибкость заработной платы в России. Препринты. Высшая школа экономики. Серия WP3/2003/04.

Гимпельсон В.Е., Ощепков А.Ю. (2010) Уровень и страх безработицы: есть ли между ними связь? Препринты. Высшая школа экономики. Серия WP3/2010/06.

Ниворожкина Л. И., Ниворожкин А. М., Арженовский С. В. (2008) Материнство и заработная плата: почему женщины с детьми зарабатывают меньше? Социальная политика: реалии ХХІ века, (3): 72-126.

Пайе А., Синявская О. (2010) Занятость женщин во Франции и России: роль детей и гендерных установок. С. В. Захаров, Л. М. Прокофьева, О. В. Синявская (ред.) Эволючия семьи в Европе: Восток-Запад. М.: НИСП: 304-352.

Пишняк А.И. (2015) Возможности и ограничения занятости женщин в Москве. Народонаселение, (1): 69-81. 
Рощин С. Ю. (2003) Предложение труда в России: микроэкономический анализ экономической активности населения. Препринты. Высшая школа экономики. Серия WP3/2003/02.

Синявская О. В., Захаров С. В., Карцева М.А. (2007) Поведение женщин на рынке труда и деторождение в современной России. Т.М. Малева, О. В. Синявская (ред.) Родители и дети, мужчины и женщины в семье и обществе. М.: НИСП: 421-476.

Aliaga C. (2005) Gender Gaps in the Reconciliation between Work and Family Life. Statistics in Focus, Population and Social Conditions, Eurostat. Available at: https://ec.europa.eu/eurostat/documents/3433488/5568556/KS-NK-05-004-EN.PDF/21a869f57c67-400e-b392-cf072ebcb3e8 (Accessed 30 января 2020).

Becker G. S. (1991) A Treatise on the Family. Cambridge: Harvard University Press.

Correll S. J., Benard S., Paik I. (2007) Getting a Job: Is There a Motherhood Penalty? American Journal of Sociology, 112 (5): 1297-1339.

Fortin N. M. (2006) Greed, Altruism, and the Gender Wage Gap. Vancouver: University of British Columbia.

Gornick J.C., Meyers M.K., Ross K.E. (1998) Public Policies and the Employment of Mothers: A Cross-National Study. Social Science Quarterly, (79):35-54.

Hakim C. (1996) The Sexual Division of Labour and Women's Heterogeneity. The British journal of sociology, 47 (1): 178-188.

Hotz V. J., Miller R. A. (1988) An Empirical Analysis of Life Cycle Fertility and Female Labor Supply. Econometrica, 56 (1): 91-118.

Jaumotte F. (2003) Labour Force Participation of Women: Empirical Evidence on the Role of Policy and Other Determinants in OECD Countries. OECD Economic Studies, (37): 51-108.

Killingsworth M. R., Heckman J. J. (1986) Female Labor Supply: A Survey. Handbook of Labor Economics, 1 (1): 105-204.

OECD (2011) Doing Better for Families. Available at: http://www.oecd.org/els/family/47849499. pdf (accessed 30 января 2020).

Popova D., Pishnyak A. (2017) Measuring Individual Material Well-being Using Multidimensional Indices: An Application Using the Gender and Generation Survey for Russia. Social Indicators Research, 130 (3): 883-910.

Rubery J., Smith M., Fagan C., Grimshaw D. (1998) Women and European Employment. London: Routledge.

Uunk W., Kalmijn M., Muffels R. (2005) The Impact of Young Children on Women's Labour Supply A Reassessment of Institutional Effects in Europe. Acta sociologica, 48 (1): 41-62.

Van Der Lippe T. (2001) The Effect of Individual and Institutional Constraints on Hours of Paid Work of Women. In: T. Van Der Lippe, L. Van Dijk (eds.) Women's Employment in a Comparative Perspective. New York: Aldine de Gruyter:221-243. 
Alina Pishnyak, Eugenia Nadezhdina

\section{EMPLOYMENT OF RUSSIAN WOMEN AFTER CHILDBIRTH: INCENTIVES AND BARRIERS}

The article examines the economic activity of women after childbirth in Russia and the incentives and barriers that exist for them in returning to employment. The birth of a child in Russia involves a number of risks to the employment of the mother. First of all, it's a risk to stay without work and there is a chance that less than favourable working conditions will be found after returning from maternity leave and child care compared to workers without children. The longer the break in employment, the higher the likelihood of employment problems. One can argue that this is solely due to the loss of skills during the maternity leave, but this obviously contributes. These facts are particularly important because families with children in Russia are consistently among the groups at the highest risk of falling into poverty. Why do some return to work (sometimes even before the end of the maternity leave), while others remain outside of the labour market? What keeps women off the labour market, and what could help them to find employment or to return to the same place? To answer these questions, we carried out qualitative analysis based on data from group interviews and a comparison of the views of unemployed and employed women with children under the age of three. We also interviewed employees - high, medium and low-skilled workers - that reflect the socio-economic heterogeneity of the population we studied. The research is also based on data from focus groups conducted in four types of settlements in Russia in 2013: the capital city, a large city, a small city, and a village.

Keywords: employment of women, labour market, working conditions, return to employment, maternity leave, childcare leave

DOI: 10.17323/727-0634-2020-18-2-221-238

\section{References}

Aliaga C. (2005) Gender Gaps in the Reconciliation between Work and Family Life. Statistics in Focus, Population and Social Conditions, Eurostat. Available at: https://ec.europa.eu/eurostat/documents/3433488/5568556/KS-NK-05-004-EN.PDF/21a869f5-7c67-400e-b392cf072ebcb3e8 (Accessed 30.01.20).

Becker G. S. (1991) A Treatise on the Family. Cambridge: Harvard University Press.

Alina I. Pishnyak - PhD (Kandidat Nauk) in Sociology, Head of the Center for Studies of Income and Living Standards, NRU HS, Moscow, Russian Federation. Email: apishniak@hse.ru

Eugenia V. Nadezhdina - PhD (Kandidat Nauk) in Cultural Studies, Assistant Professor, Faculty of Social Sciences, School of Sociology, NRU HS, Moscow, Russian Federation. Email: nadezhda@hse.ru 
Correll S. J., Benard S., Paik I. (2007) Getting a Job: Is There a Motherhood Penalty? American Journal of Sociology, 112 (5): 1297-1339.

Fortin N.M. (2006) Greed, Altruism, and the Gender Wage Gap. Vancouver: University of British Columbia.

Gimpel'son V.E., Kapelyushnikov R. I., Ratnikova T. A. (2003) Veliki li glaza u strakha? Strakh bezrabotitsy i gibkost' zarabotnoy platy v Rossii [Does Fear Have Big Eyes? The Fear of unemployment and Wage Flexibility in Russia]. Preprinty. Vysshaya shkola ekonomiki [Higher School of Economics Preprints], WP3/2003/04.

Gimpel'son V.E., Oshchepkov A. Y. (2010) Uroven' i strakh bezrabotitsy: est' li mezhdu nimi svyaz'? [The Level and Fear of Unemployment: Is There a Connection between Them?]. Preprinty. Vysshaya shkola ekonomiki [Higher School of Economics Preprints], WP3/2010/06.

Gornick J. C., Meyers M.K., Ross K. E. (1998) Public Policies and the Employment of Mothers: A Cross-National Study. Social Science Quarterly, (79):35-54.

Hakim C. (1996) The Sexual Division of Labour and Women's Heterogeneity. The British Journal of Sociology, 47 (1): 178-188.

Hotz V. J., Miller R.A. (1988) An Empirical Analysis of Life Cycle Fertility and Female Labor Supply. Econometrica, 56 (1): 91-118.

Jaumotte F. (2003) Labour Force Participation of Women: Empirical Evidence on the Role of Policy and Other Determinants in OECD Countries. OECD Economic Studies, (37): 51-108.

Killingsworth M. R., Heckman J. J. (1986) Female Labor Supply: A Survey. Handbook of Labor Economics, 1 (1): 105-204.

Nivorozhkina L.I., Nivorozhkin A. M., Arzhenovskiy S. V. (2008) Materinstvo i zarabotnaya plata: pochemu zhenshchiny s det'mi zarabatyvayut men'she? [Maternity and Wages: Why do Women with Children Earn Less?]. Sotsial'naya politika: realii XXI veka [Social Policy: The Realities of the 21st Century], (3): 72-126.

OECD (2011) Doing Better for Families. Available at: http://www.oecd.org/els/family/47849499. pdf (accessed 30 January 2020).

Paye A., Sinyavskaya O. (2010) Zanyatost' zhenshchin vo Frantsii i Rossii: rol' detey i gendernykh ustanovok [Women's Employment in France and Russia: The Role of Children and Gender Attitudes]. In: S. V. Zakharov, L. M. Prokof'eva, O. V. Sinyavskaya (eds.) Evolyutsiya sem'i v Evrope: Vostok-Zapad [Family Evolution in Europe: East-West]. Moscow: NISP: 304-352.

Pishnyak A. I. (2015) Vozmozhnosti i ogranicheniya zanyatosti zhenshchin v Moskve [Opportunities and restrictions on women's employment in Moscow]. Narodonaselenie [Population], (1): 69-81.

Popova D., Pishnyak A. (2017) Measuring Individual Material Well-being Using Multidimensional Indices: An Application Using the Gender and Generation Survey for Russia. Social Indicators Research, 130 (3): 883-910.

Roshchin S. Y. (2003) Predlozhenie truda v Rossii: mikroekonomicheskiy analiz ekonomicheskoy aktivnosti naseleniya [Labor Supply in Russia: Microeconomic Analysis of the Economic Activity of the Population]. Preprinty. Vysshaya shkola ekonomiki [Higher School of Economics Preprints], WP3/2003/02. 
Rubery J., Smith M., Fagan C., Grimshaw D. (1998) Women and European Employment. London: Routledge.

Sinyavskaya O.V., Zakharov S. V., Kartseva M.A. (2007) Povedenie zhenshchin na rynke truda i detorozhdenie v sovremennoy Rossii [The Behaviour of Women in the Labour Market and Childbirth in Modern Russia]. In: T.M. Maleva, O. V. Sinyavskaya (eds.) Roditeli i deti, muzhchiny i zhenshchiny v sem'e i obshchestve [Parents and Children, Men and Women in Family and Society]. Moscow: NISP:421-476.

Uunk W., Kalmijn M., Muffels R. (2005) The Impact of Young Children on Women's Labour Supply. A Reassessment of Institutional Effects in Europe. Acta Sociologica, 48 (1): 41-62.

Van Der Lippe T. (2001) The Effect of Individual and Institutional Constraints on Hours of Paid Work of Women. In: T. Van Der Lippe, L. Van Dijk (eds.) Women's Employment in a Comparative Perspective. New York: Aldine de Gruyter: 221-243. 